\title{
Development and Validation of a Low-Cost and Simple Simulator for Microlaryngeal Surgery
}

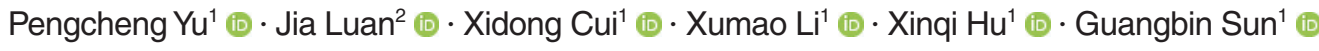 \\ ${ }^{1}$ Department of Otorhinolaryngology-Head and Neck Surgery, Huashan Hospital, Fudan University, Shanghai; \\ ${ }^{2}$ Outpatient Department, Huashan Worldwide Medical Center, Shanghai, China
}

Objectives. The simulation of microlaryngeal skills is rarely seen in surgical training, but it is particularly important in phonomicrosurgery. This study described and validated the laryngeal surgical simulator through surgical training.

Methods. A simple and low-cost simulator was developed for the fixation of the suspension laryngoscope and porcine larynges. Twenty participants with work skills and experience did preparation before training, and performed suture and carbon dioxide $\left(\mathrm{CO}_{2}\right)$ laser cordectomy for simulator evaluation. The results were proposed by the aspects of time taken for each procedure, the global rating scale, a procedure-specific assessment, and a post-simulation questionnaire.

Results. All participants completed the preparation within 9 minutes and reached the conclusion that the microlaryngeal surgical simulator was helpful in improving their surgical skills. The performance of experts was superior to that of novices in both suture and $\mathrm{CO}_{2}$ laser cordectomy.

Conclusion. This simulator could be easily assembled and was successfully validated by microlaryngeal surgical training both subjectively and objectively. It may be helpful to clinicians in microlaryngeal skills.

Keywords. Larynx; Microsurgery; Simulation Training; Education

\section{INTRODUCTION}

Microlaryngeal surgery had become the mainstream of surgical treatment for early-stage pharynx and larynx tumors over the last several decades $[1,2]$. It also met with the prevalent concept of minimally invasive treatment. However, there are limitations that constrain the application of microlaryngeal surgery. Under some circumstances, the difficult exposure of vocal folds in particular patients led to the failure of surgery [3]. Some fatal complications might occur during the procedure of suspension la-

\footnotetext{
- Received April 12, 2019

Revised June 3, 2019

Accepted June 17, 2019

- Corresponding author: Guangbin Sun

Department of Otorhinolaryngology-Head and Neck Surgery, Huashan Hospital, Fudan University, No. 12, Middle Urumqi Rd, Shanghai 200040, China

Tel: +86-21-52887053, Fax: +86-21-52888138

E-mail: sgb223@hotmail.com

*The first two authors contributed equally to this study.
}

ryngoscope, such as severe bradycardia and asystole [4,5]. Mastery of microlaryngeal surgical skills was difficult without devices similar to the suspension laryngoscope due to the narrow operating perspective. Thus, unskilled clinicians were not able to minimize the injury to the normal tissue and avoid unnecessary emergencies on actual patients, which caused poor surgical results. Due to the lack of microlaryngeal surgical training programs, clinicians have few chances to practice microsurgical skills either in the operating room or outside the surgery. Even experts need to practice new surgical techniques many times before operating on actual patients. Therefore, it is of great importance to design a proper simulator for surgical skills and experimental teaching programs. Some simulators have been reported before, yet none was widely applied [6-9].

Here, we developed a simple and effective simulator and applied it into a national continuing education seminar for three consecutive years. We introduced three methods to objectively assess the validity of the simulator, including time taken for each procedure, a procedure-specific assessment, and a modified

Copyright (C) 2020 by Korean Society of Otorhinolaryngology-Head and Neck Surgery.

This is an open-access article distributed under the terms of the Creative Commons Attribution Non-Commercial License (https://creativecommons.org/licenses/by-nc/4.0)

which permits unrestricted non-commercial use, distribution, and reproduction in any medium, provided the original work is properly cited. 

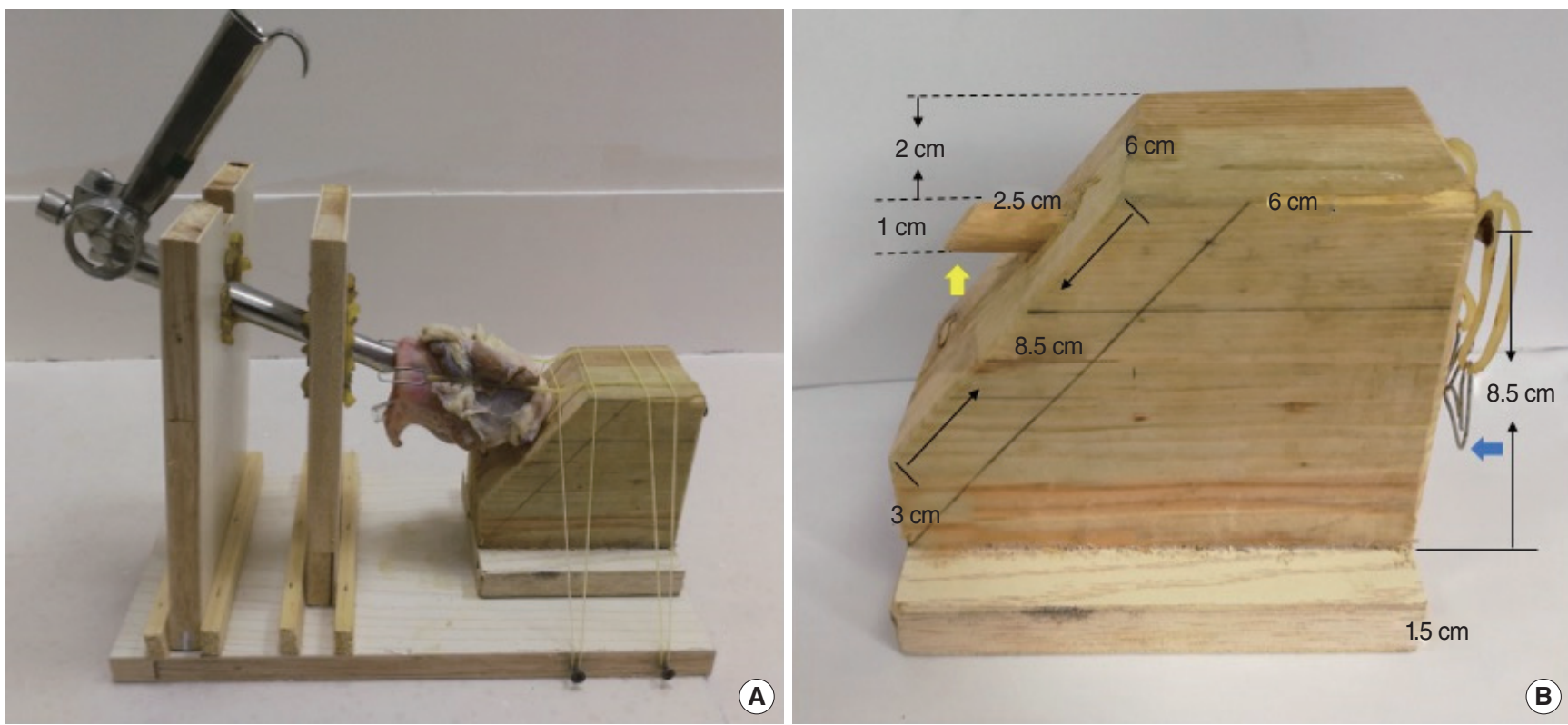

Fig. 1. (A) The simulator with a suspension laryngoscope and the porcine larynx. (B) The porcine larynx can be inserted into the raised portion (yellow arrow) and held by clips (blue arrow). The side length of one component was shown.

global rating scale from the Objective Structured Assessment of Technical Skill (OSATS) [10,11].To subjectively assess the simulator, all participants were required to complete the post-simulation survey.

\section{MATERIALS AND METHODS}

\section{Description of the device}

Porcine larynges were used in the simulator. The simulator was weighted around $1.2 \mathrm{~kg}$ and consisted of four different components that were made of wood: three of them were placed on a pedestal with four blocks and four nails, and porcine larynges could be inserted into the raised portion of a component and held by several clips (Fig. 1). Holes with different shapes and sizes were designed for the fixation of the suspension laryngoscope (Tonglu Youshi Medical Devices Co., Hangzhou, China) (Fig. 2).

During the practice, porcine larynges were required to be a consistent size. The trachea was transected at the second tracheal ring for fixation. All these specimens were stored at $4^{\circ} \mathrm{C}$ and

\section{H I G H L I G G H T S}

- We developed a low-cost and simple simulator for microlaryngeal surgery.

- Porcine larynges were used in our simulator.

- Surgeries like suture and carbon dioxide $\left(\mathrm{CO}_{2}\right)$ laser cordectomy could be performed in the simulator.

- The simulator could be helpful for both residents and experts. required at least 20 minutes to defrost by running water. This study was approved by the Institutional Review Board of Huashan Hospital (KY2018-229).

\section{Participants}

Five experts and 15 novices from the Otorhinolaryngology Head and Neck Surgery Department took part in this study. Experts were defined as senior surgeons with at least 10 years of working experience, and novices were defined as residents with less than 3 years of working experience. All participants were right-handed and signed an informed consent form before the training.

\section{Procedures}

All participants completed the following preparation before training as following: first, they assembled different components into the simulator. Then, the porcine larynx and the suspension laryngoscope were fixed into the simulator (Fig. 3).

After preparation, two training procedures were performed on the simulator, including suture (7-0 prolene) and carbon dioxide $\left(\mathrm{CO}_{2}\right)$ laser cordectomy ( $4 \mathrm{~W}$ of laser energy). Both procedures were required an appropriate exposure of vocal folds of porcine larynges under microscope (Moller VM500; MOLLERWEDEL, Wedel, Germany). All participants created a small mucosal flap on the left vocal fold using a laryngeal knife and knotted to close the flap with two curved forceps under microscopic vision [12]. They also needed to control the movement of laser spot and remove the ipsilateral vocal fold completely by $\mathrm{CO}_{2}$ laser (type II cordectomy [13]). Each procedure was video-recorded without revealing participant identities. 

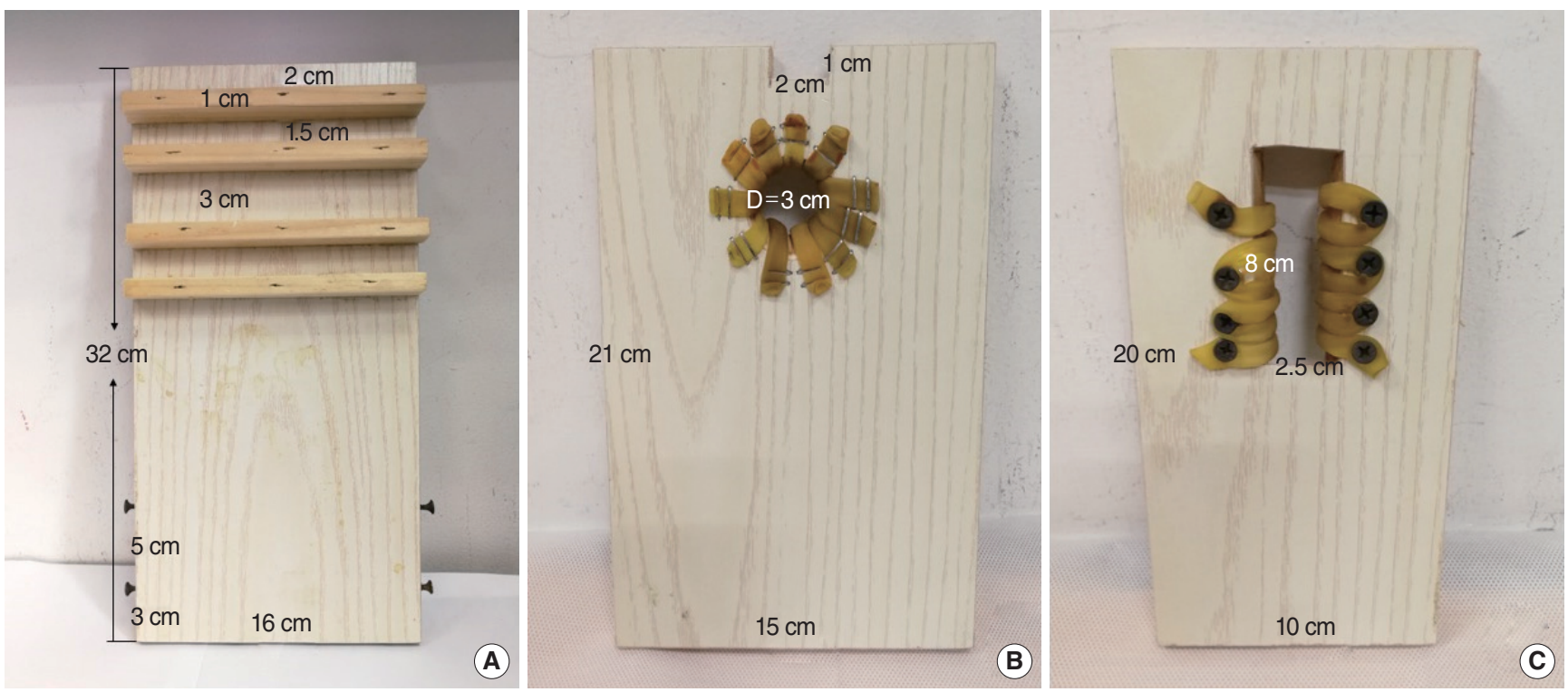

Fig. 2. Three different components of the simulator were made according to the specified parameters. (A) A pedestal with four blocks and four nails. (B) The component to let through the suspension laryngoscope. (C) The component to vertically adjust the suspension laryngoscope. D, diameter.

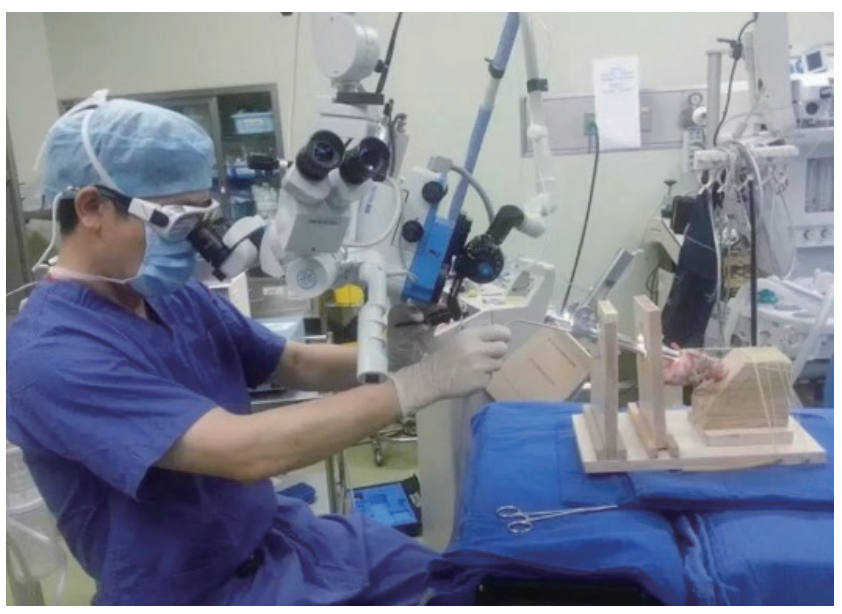

Fig. 3. A trainee was performing carbon dioxide $\left(\mathrm{CO}_{2}\right)$ laser cordectomy on the simulator under microscope.

\section{Statistical analysis}

The time taken for preparation and the other two training procedures was recorded during the procedure. After simulating training, all participants completed a Likert-scale questionnaire with responses listed as 1-5 (strongly disagree-strongly agree). Twenty anonymous video recordings were reviewed and scored by other three experts of our institution using the modified global rating assessment (each scored 1-5, maximum 30) (Supplementary Table 1) and a 35-point procedure-specific rating scale. The procedure-specific assessment of both $\mathrm{CO}_{2}$ cordectomy and suture (Table 1) contained seven items grade from 1 (unable to perform) to 5 (perform expertly), respectively. Internal consistency was evaluated by calculating Cronbach's alpha and the intraclass correla-
Table 1. Specific procedures of $\mathrm{CO}_{2}$ laser cordectomy and suture

\begin{tabular}{|c|c|}
\hline Step for $\mathrm{CO}_{2}$ laser cordectomy & Step for suture \\
\hline $\begin{array}{l}\text { 1. Appropriate exposure under } \\
\text { microscope }\end{array}$ & $\begin{array}{l}\text { 1. Appropriate exposure under } \\
\text { microscope }\end{array}$ \\
\hline 2. Adjust the spot size & 2. Create a small mucosal flap \\
\hline $\begin{array}{l}\text { 3. Control the movement of laser } \\
\text { spot }\end{array}$ & 3. Hold the needle properly \\
\hline $\begin{array}{l}\text { 4. Incise between the vocal } \\
\text { ligament and the vocal muscle }\end{array}$ & $\begin{array}{l}\text { 4. Pass the needle through the } \\
\text { mucosal flap }\end{array}$ \\
\hline 5. Suck out smoke & $\begin{array}{l}\text { 5. Cut the end of the suture thread } \\
\text { with the needle }\end{array}$ \\
\hline $\begin{array}{l}\text { 6. Complete removal of unilateral } \\
\text { vocal fold }\end{array}$ & $\begin{array}{l}\text { 6. Tie a knot tightly with two curved } \\
\text { forceps }\end{array}$ \\
\hline 7. Seize the resected vocal fold & 7. Cut the excess suture threads \\
\hline
\end{tabular}

$\mathrm{CO}_{2}$, carbon dioxide.

tion coefficient (ICC) was used for assessing interrater reliability. All data from two groups were compared using the Mann-Whitney $U$-test. Significance was set at $P<0.05$. Pearson correlation coefficients were calculated to compare the correlation between the global rating score and the procedure-specific rating scale.

\section{RESULTS}

All participants completed the preparation within 9 minutes. The mean time to perform suture (Fig. 4A) was $6.4 \pm 1.0$ minutes for experts and 17.0 \pm 6.6 minutes for novices, and this difference was statistically significant $(P<0.001)$. Experts spent less time than novices in $\mathrm{CO}_{2}$ laser cordectomy $(P<0.05)$ (Table 2, Fig. 4B). 

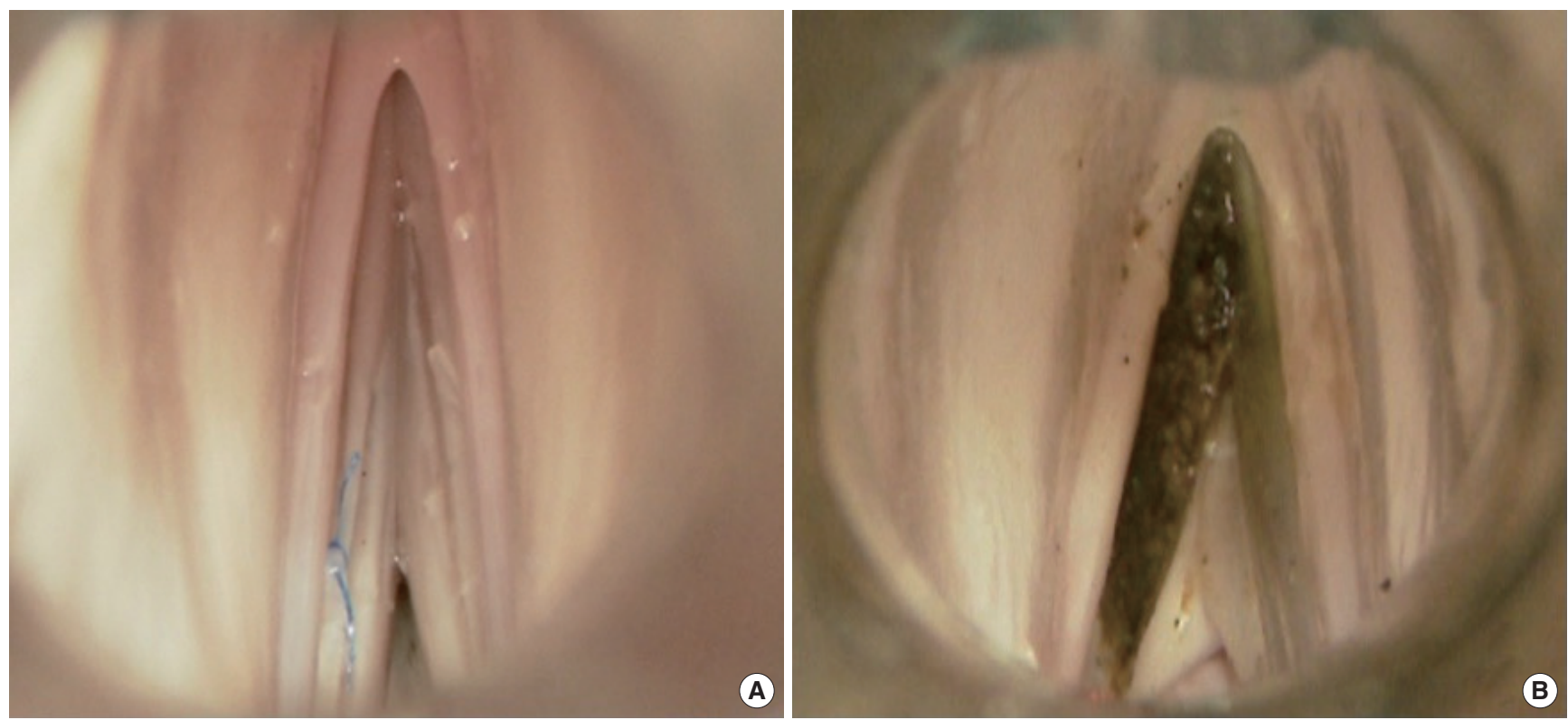

Fig. 4. (A) The specimen image of suture on the left vocal fold. (B) The specimen image of carbon dioxide $\left(\mathrm{CO}_{2}\right)$ laser cordectomy of the left vocal fold.

Table 2. Mean time to perform each procedure

\begin{tabular}{lccr}
\hline Procedure & Expert $(\mathrm{min})$ & Novice $(\mathrm{min})$ & $P$-value \\
\hline Preparation & $5.2 \pm 2.1$ & $4.4 \pm 1.3$ & 0.266 \\
Suture & $6.4 \pm 1.0$ & $17.0 \pm 6.6$ & $<0.001$ \\
$\mathrm{CO}_{2}$ laser cordectomy & $3.9 \pm 1.1$ & $5.8 \pm 1.6$ & 0.025 \\
\hline
\end{tabular}

Values are presented as mean \pm standard deviation.

$\mathrm{CO}_{2}$, carbon dioxide

According to the post-simulation survey, all participants were satisfied with the assembly, validity, and usefulness of the simulator, all with mean scores no less than 4.5 (Table 3). Assessment of the level of difficulty for training procedures using the device differed significantly between experts and novices $(P<0.01)$.

Global rating scores for experts were significantly better than those for novices both in suture (mean, $24.6 \pm 2.1$ vs. $17.5 \pm 4.8$, respectively; $P<0.01$ ) and $\mathrm{CO}_{2}$ laser cordectomy (mean, 25.8土 1.3 vs. $21.0 \pm 4.0$, respectively; $P<0.05$ ) (Table 4 ). Both the global rating system and the procedure-specific rating system demonstrated strong internal consistency (Cronbach's alpha >0.90) and the ICC values ranged from 0.81 to 0.94 among two assessment systems. Pearson rank correlation showed a strong correlation between the global rating score system and the procedurespecific rating score system in $\mathrm{CO}_{2}$ laser cordectomy and suture, at the correlation coefficient of 0.919 for and 0.968 , respectively (Fig. 5).

\section{DISCUSSION}

With advanced surgical equipment, anesthetic techniques, and
Table 3. Mean score of a Likert-scale questionnaire ranging from 1 to 5 (strongly disagree-strongly agree)

\begin{tabular}{lccc}
\hline Survey question & Expert & Novice & $P$-value \\
\hline Simulator easy to assemble & $4.8 \pm 0.4$ & $4.9 \pm 0.4$ & 0.866 \\
Porcine anatomy similar to human & $4.6 \pm 0.5$ & $4.5 \pm 0.7$ & 0.866 \\
Tissue felt realistic & $4.6 \pm 0.5$ & $4.5 \pm 0.8$ & 1.000 \\
Training is in high fidelity & $4.8 \pm 0.4$ & $4.8 \pm 0.4$ & 1.000 \\
Appropriate level of difficulty & $3.8 \pm 0.4$ & $2.6 \pm 0.6$ & 0.004 \\
Helpful to improve surgical skills & $4.8 \pm 0.4$ & $4.9 \pm 0.4$ & 0.866 \\
Overall satisfaction is high & $4.8 \pm 0.4$ & $4.7 \pm 0.6$ & 1.000 \\
\hline
\end{tabular}

Values are presented as mean \pm standard deviation.

Table 4. Assessment score for two training procedures

\begin{tabular}{lccccc}
\hline Variable & Expert & Novice & $P$-value $\begin{array}{c}\text { Cronbach's } \\
\text { alpha }\end{array}$ & ICC \\
\hline Micro suture & & & & & \\
$\quad$ Global & $24.6 \pm 2.1$ & $17.5 \pm 4.8$ & 0.006 & 0.96 & 0.88 \\
$\begin{array}{l}\text { Procedure-specific } \\
\mathrm{CO}_{2} \text { laser cordectomy }\end{array}$ & $32.0 \pm 2.0$ & $23.8 \pm 6.2$ & 0.008 & 0.98 & 0.94 \\
$\quad$ Global & & & & \\
$\quad$ Procedure-specific & $31.6 \pm 2.1$ & $25.4 \pm 4.3$ & 0.002 & 0.96 & 0.90 \\
\hline
\end{tabular}

Values are presented as mean \pm standard deviation.

ICC, intraclass correlation coefficient; $\mathrm{CO}_{2}$, carbon dioxide.

the widespread concept of minimally invasive treatment, microlaryngeal surgery has gradually become prevalent in laryngology.

However, young clinicians have few chances to perform microlaryngeal surgery independently due to the extremely high precision requirement and the high risk during the surgery. Although there are many anatomical and surgical training courses 

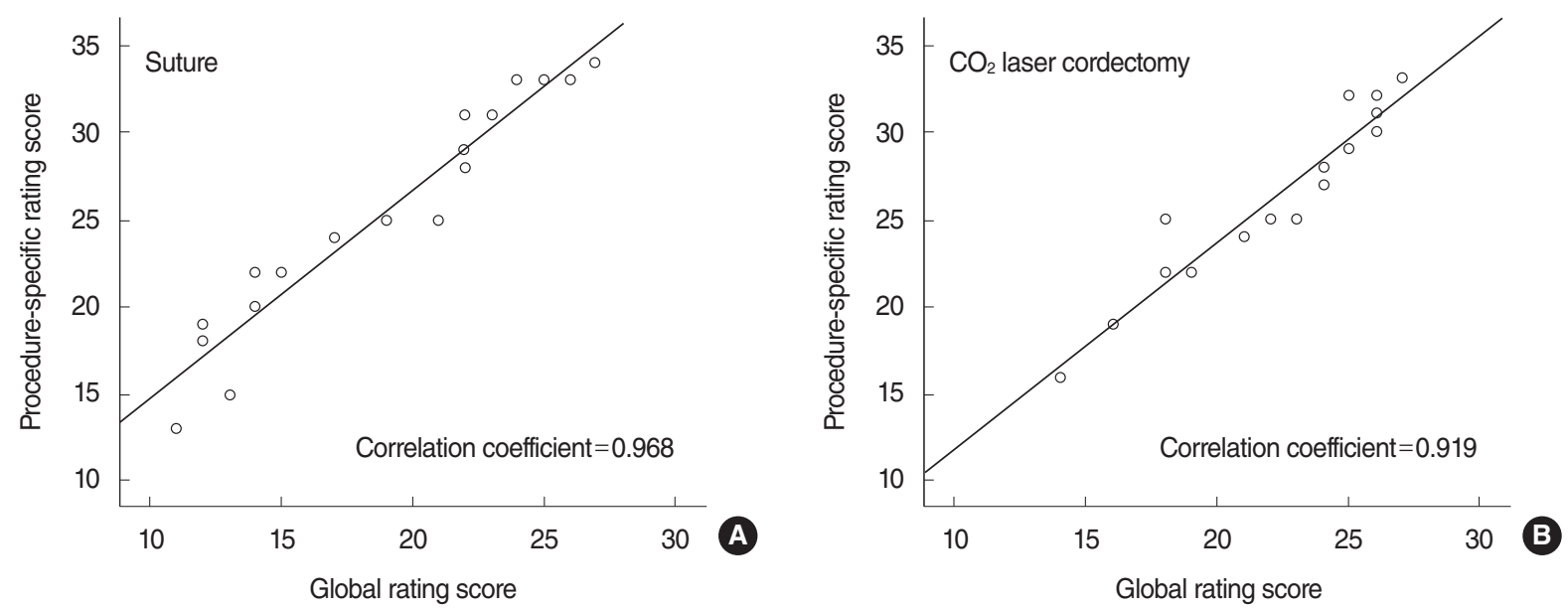

Fig. 5. Direct correlation between the global rating score and the procedure-specific rating score for suture $(A)$ and carbon dioxide $\left(\mathrm{CO}_{2}\right)$ laser cordectomy (B). Pearson correlation coefficients are shown for each procedure.

in the world, opportunities for training in microlaryngeal surgery are rarely seen due to the inadequate training equipment.

Previously, laryngeal dissection station was firstly designed by Dailey et al. [6], and the larynx was affixed with needles. Fleming et al. [8] utilized a laryngoscope with adjustable stand for suspension, but it required the use of operating room staff. Zambricki et al. [14] reported a low-cost but unadjustable phonomicrosurgical simulation model, and they used grapes for surgical training. In our study, the larynx could be easily fixed with clips and rubber bands. Moreover, the simulator was convenient for carrying and storing by its lightweight and demountable characteristics. Participants should pay attention to avoiding any damage to the wooden simulator, even though there was no accident reported previously. All participants completed the preparation within 9 minutes, indicating that the simulator could be easily installed and disassembled. There was a difference between the assessment of the level of difficulty for training procedures. We assumed that most young clinicians know $\mathrm{CO}_{2}$ laser cordectomy well but know little about suture because suture technology is seldom used in microlaryngeal surgery.

The most ideal specimen for surgical training is the cadaveric human larynx. Unfortunately, it is difficult to obtain and costs a lot. Therefore, animal larynges and artificial materials were alternative frequently used in the past [15-17]. There is a difference between human and animal larynges in the dissection structure and function, however previous research proposed that porcine larynx might be a superior model for phonatory research $[18,19]$. Sheep head and neck model was reported and each specimen would cost 20 to 28 dollars [20]. In our method, we provided fresh and inexpensive (less than 3 dollars per specimen) porcine larynges. All specimens were purchased from a regular slaughterhouse and were processed under the rules of laboratory to reduce the potential risk of zoonotic disease. All participants considered the anatomy of the porcine larynx to be similar to that of the human larynx and agreed that the training could be helpful to improve their surgical skills in real surgical scenarios. Using manikins for training might provide an immersive experience for trainees by mimicking the human airway anatomy but increased costs [8,17]. Although Holliday et al. [16] developed a low-cost simulator, it was not be suitable for laser cordectomy due to its characteristic of rubber bands representing vocal folds.

To make the assessment of surgical skills more objective, valid, and reliable, we introduced the procedure-specific system and the global rating system. Our evaluation showed that both scoring systems demonstrated strong internal consistency and excellent intrarater reliability. In our study, expert performance was significantly superior to novice performance for both suture and $\mathrm{CO}_{2}$ laser cordectomy. These procedures were intricate and required surgical proficiency. Most novices could not perform resection precisely between the vocal ligament and the vocal muscle. Although novices watched and participated in these procedures many times, most of them had no chance to perform these surgeries by themselves. The high correlations between global rating scale and the procedure-specific assessment suggested that both scoring systems were measuring the same quality. Taken together, all these results showed that the validation of the simulator for suture and $\mathrm{CO}_{2}$ laser cordectomy were accurate and objective, suggesting that our simulator had strong potential to further applied in the laryngeal microsurgery training in future. There might be some limitations in this study due to its small sample size and lack of a follow-up evaluation of the improvement of the participants in the medical surgery. It is high recommended to recruit more participants and comprehensive evaluation and follow-up system to improve our simulator. This simulator could be easily assembled and was successfully validated by microlaryngeal surgical training both subjectively and objectively. It may be helpful to clinicians in microlaryngeal skills. 


\section{CONFLICT OF INTEREST}

No potential conflict of interest relevant to this article was reported.

\section{ACKNOWLEDGMENTS}

This study was supported by a grant (No. yg2017/007) from Fudan University-SIBET Medical Engineering Joint Fund, Shanghai, China.

\section{SUPPLEMENTARY MATERIAL}

Supplementary material can be found via https://doi.org/10. 21053/ceo.2019.00556.

\section{ORCID}

Pengcheng Yu https://orcid.org/0000-0001-5170-3134

Jia Luan https://orcid.org/0000-0002-8914-3635

Xidong Cui https://orcid.org/0000-0002-1405-0338

Xumao Li https://orcid.org/0000-0001-6019-8109

Xinqi Hu https://orcid.org/0000-0003-2374-2982

Guangbin Sun https://orcid.org/0000-0002-8686-9553

\section{AUTHOR CONTRIBUTIONS}

Conceptualization: GS. Data curation: PY, JL. Formal analysis: JL, XC. Funding acquisition: GS. Methodology: XL, XH. Project administration: XC, XL, XH.Visualization: XC.Writing - original draft: PY.Writing - review \& editing: PY, JL, GS.

\section{REFERENCES}

1. Jackel MC, Martin A, Steiner W. Twenty-five years experience with laser surgery for head and neck tumors: report of an international symposium, Gottingen, Germany, 2005. Eur Arch Otorhinolaryngol. 2007 Jun;264(6):577-85.

2. Steuer CE, El-Deiry M, Parks JR, Higgins KA, Saba NF. An update on larynx cancer. CA Cancer J Clin. 2017 Jan;67(1):31-50.
3. Xidong C, Xia Z, Chenjie X, Wenhong Y, Huichang Y, Jiaqi J. Management of difficult suspension laryngoscopy using a GlideScope(R) Video Laryngoscope. Acta Otolaryngol. 2012 Dec;132(12):1318-23.

4. Latuska RF, Kuhl NO, Garrett CG, Berry JM, Gelbard A. Severe bradycardia associated with suspension laryngoscopy. Laryngoscope. 2016 Apr;126(4):949-50.

5. Glassman SH, Green MS, Brodsky M.Asystole following reintubation during suspension laryngoscopy. Case Rep Anesthesiol. 2012;2012: 916306.

6. Dailey SH, Kobler JB, Zeitels SM.A laryngeal dissection station: educational paradigms in phonosurgery. Laryngoscope. 2004 May; 114(5):878-82.

7. Contag SP, Klein AM, Blount AC, Johns MM 3rd. Validation of a laryngeal dissection module for phonomicrosurgical training. Laryngoscope. 2009 Jan;119(1):211-5.

8. Fleming J, Kapoor K, Sevdalis N, Harries M.Validation of an operating room immersive microlaryngoscopy simulator. Laryngoscope. 2012 May;122(5):1099-103.

9. Ainsworth TA, Kobler JB, Loan GJ, Burns JA. Simulation model for transcervical laryngeal injection providing real-time feedback. Ann Otol Rhinol Laryngol. 2014 Dec;123(12):881-6.

10. Martin JA, Regehr G, Reznick R, MacRae H, Murnaghan J, Hutchison C, et al. Objective structured assessment of technical skill (OSATS) for surgical residents. Br J Surg. 1997 Feb;84(2):273-8.

11. Moorthy K, Munz Y, Sarker SK, Darzi A. Objective assessment of technical skills in surgery. BMJ. 2003 Nov;327(7422):1032-7.

12. Tsuji DH, Nita LM, Hachiya A, Imamura R, Sennes LU. T-shaped microsuture: a new suture technique for laryngeal microsurgery. $\mathrm{J}$ Voice. 2009 Nov;23(6):739-42.

13. Remacle M, Eckel HE, Antonelli A, Brasnu D, Chevalier D, Friedrich $\mathrm{G}$, et al. Endoscopic cordectomy: a proposal for a classification by the Working Committee, European Laryngological Society. Eur Arch Otorhinolaryngol. 2000;257(4):227-31.

14. Zambricki EA, Bergeron JL, DiRenzo EE, Sung CK. Phonomicrosurgery simulation: a low-cost teaching model using easily accessible materials. Laryngoscope. 2016 Nov;126(11):2528-33.

15. Dedmon MM, Paddle PM, Phillips J, Kobayashi L, Franco RA, Song PC. Development and validation of a high-fidelity porcine laryngeal surgical simulator. Otolaryngol Head Neck Surg. 2015 Sep;153(3): 420-6.

16. Holliday MA, Bones VM, Malekzadeh S, Grant NN. Low-cost modular phonosurgery training station: development and validation. Laryngoscope. 2015 Jun;125(6):1409-13.

17. Nixon IJ, Palmer FL, Ganly I, Patel SG. An integrated simulator for endolaryngeal surgery. Laryngoscope. 2012 Jan;122(1):140-3.

18. Jiang JJ, Raviv JR, Hanson DG. Comparison of the phonation-related structures among pig, dog, white-tailed deer, and human larynges. Ann Otol Rhinol Laryngol. 2001 Dec;110(12):1120-5.

19. Alipour F, Jaiswal S, Vigmostad S. Vocal fold elasticity in the pig, sheep, and cow larynges. JVoice. 2011 Mar;25(2):130-6.

20. Isaacson G, Ianacone DC, Soliman AM. Ex vivo ovine model for suspension microlaryngoscopy training. J Laryngol Otol. 2016 Oct;130 (10):939-42. 